\title{
Colitis caused by non-steroidal anti-inflammatory drugs
}

\author{
S. Ravi ${ }^{1}$, A.C. Keat $^{2}$ and E.C.B. Keat ${ }^{1}$ \\ ${ }^{I}$ Cuckfield Hospital, Cuckfield, West Sussex, and ${ }^{2}$ Westminster Hospital, Horseferry Road, London \\ SWIP $2 A P, U K$.
}

\begin{abstract}
Summary: Four cases of acute proctocolitis associated with non-steroidal anti-inflammatory drug therapy are presented. The drugs implicated were flufenamic acid, mefenamic acid, naproxen and ibuprofen. After resolution of symptoms and signs of proctocolitis three of the four patients were subsequently rechallenged with the implicated drug: in each there was a rapid relapse.
\end{abstract}

\section{Introduction}

Ulcerative colitis is a disease of unknown aetiology with characteristic clinical features and a protracted course. A similar clinical picture, but running a shorter and usually benign course, is occasionally seen following the administration of certain drugs. This was first noticed following the administration of antibiotics, often with pseudomembrane formation. Later, this was shown to be associated with infection by toxigenic Clostridium difficile. Until 1978, most cases were associated with treatment with clindamycin but since that time nearly all antibiotics have been implicated. Other drugs capable of causing proctocolitis, though by different mechanisms, include phenindione (Keat \& Tanser, 1966), penicillamine (Hickling \& Fulbi, 1979), gold salts (Fam et al., 1980), methyl dopa (Graham et al., 1981), cimetidine (Collins, 1982) and methotrexate (Atherton et al., 1984). Inflammatory bowel disease resembling Crohn's disease, though nearly always with rectal sparing, has also been associated with oral contraceptives (Tedesco et al., 1982).

In contrast to non-specific diarrhoea, which is a well-known side effect of anti-rheumatic medication, ulcerative proctocolitis has been associated with ingestion of salicylate (Pearson et al., 1983) and mefenamic acid (Hall et al., 1983; Phillips et al., 1983; Edwards et al., 1983; Rampton \& Tapping, 1983; Williams \& Glazier, 1983) usually after prolonged exposure to the drug. We report four cases of proctocolitis in which three further non-steroidal anti-inflammatory drugs (NSAIDs) are implicated. In three out of four cases colitis recurred on rechallenge. None of the patients had suffered from colitis previously. Possible mechanisms of induction of colitis are briefly discussed.

Correspondence: A.C. Keat, M.D., M.R.C.P.

Accepted: 20 January 1986

\section{Case reports}

\section{Case 1}

A 77 year old woman was referred with intermittent bleeding per rectum for 6 months, associated for the last 2 months with bloody diarrhoea up to eight times daily. Previously, she had had troublesome symptoms from osteoarthritis of her back and knees for which she had been prescribed flufenamic acid $200 \mathrm{mg}$ thrice daily. Her general health had remained good but she appeared pale and her haemoglobin was reduced to $8 \mathrm{~g} / \mathrm{dl}$. Apart from osteoarthritis at the knees there were no abnormal physical signs. Sigmoidoscopy revealed an inflamed, bleeding mucosa in the rectum and sigmoid colon and rectal biopsy showed heavy mucosal infiltration with lymphocytes and plasma cells. Stool cultures were negative for bacterial and fungal pathogens and parasites and a barium enema showed loss of haustration in the descending and sigmoid colon. Flufenamic acid was discontinued and after 2 weeks her bowels had returned to normal with a dramatic improvement in the sigmoidoscopic appearances. She was subsequently re-challenged with $200 \mathrm{mg}$ of flufenamic acid daily; she discontinued the tablets after $\mathbf{4 8}$ hours because of recurrence of diarrhoea.

\section{Case 2}

A 73 year old woman complained of diarrhoea for 3 months with six to seven bowel actions daily associated with tenesmus and the passage of blood and mucus. Previously, she had complained of painful knees and 9 days before the onset of diarrhoea, she had been prescribed mefenamic acid $500 \mathrm{mg}$ t.d.s. She appeared well with mild osteoarthritis of the knees but no other abnormal physical signs. Sigmoidoscopy 
revealed actively inflamed rectal mucosa with contact bleeding and blood-stained mucus. Stool cultures were negative. Mefenamic acid was discontinued and a barium enema arranged. Her symptoms rapidly subsided, however, and she cancelled the examination. Repeat sigmoidoscopy, two weeks later, showed the mucosa to have returned almost to normal with only mild injection and no contact bleeding. She was subsequently re-challenged with mefenamic acid $250 \mathrm{mg} /$ day; she developed loose motions again and discontinued medication after 72 hours. Following this she remained well and, when reviewed several months later, had had no further bowel symptoms.

\section{Case 3}

A 67 year old woman was admitted to hospital with abdominal pain and severe watery diarrhoea at hourly intervals containing blood and mucus. She had developed superficial thrombophlebitis of her right calf two and a half weeks previously for which she had been prescribed a 6 day course of flucloxacillin. The leg remained painful and, 8 days after discontinuing the antibiotic, she was prescribed naproxen $250 \mathrm{mg}$ twice daily. After 2 days she developed diarrhoea, which became increasingly frequent with blood staining, prostration, anorexia and weight loss and necessitated admission to hospital. At that time she was thin and dehydrated but not anaemic and the abdomen was diffusely tender but not distended. Sigmoidoscopy showed acutely inflamed mucosa in the rectum and sigmoid colon. The stools contained leucocytes and red cells but cultures were negative for fungal and bacterial pathogens, including $C$. difficile, cysts, ova and parasites. A barium enema examination showed lack of haustration of the descending and sigmoid colon with a fine granular appearance of the mucosal lining. Naproxen was stopped and she was treated with prednisdone enemas daily for 7 days, during which time her stools returned to normal. She was discharged 3 days later requiring no treatment. On rechallenge with naproxen $125 \mathrm{mg} /$ day, 3 weeks later, she developed looseness of the bowels after 3 days and symptoms similar to the onset of her previous illness. The patient, therefore, discontinued naproxen.

\section{Case 4}

A 69 year old woman was admitted to hospital with a history of frequent bloody diarrhoea and tenesmus for 2 days together with malaise and feeling unwell. She had suffered from osteoarthritis of the hips for many years for which she had taken one aspirin tablet twice daily until a week before admission. At that time, her general practitioner had changed her prescription to ibuprofen $400 \mathrm{mg}$ twice daily. She developed diarrhoea 5 days later. Her general health was good and apart from mild tenderness in the abdomen there were no abnormal physical signs in the alimentary system. Sigmoidoscopy showed an inflamed bleeding rectal mucosa. Stool cultures were negative for pathogens and a barium enema revealed only scattered diverticula. Five days after stopping ibuprofen her symptoms had abated and repeat sigmoidoscopy after a further 5 days showed clearing of the inflammation. Thereafter, she remained well and when reviewed 3 weeks after discharge, had no gastrointestinal symptoms. She did not agree to re-challenge.

\section{Discussion}

Four different NSAIDs, prescribed for osteoarthritis or phlebitis are implicated in the development of proctocolitis in these patients. None of the patients had previously suffered from colitis, all rapidly became symptom-free on cessation of treatment and, in three patients, symptoms of colitis rapidly returned on re-challenge with the drug. A diagnosis of proctocolitis was made by the presence of diarrhoea varying from four to twelve or more times daily, inflamed mucosa on sigmoidoscopy and negative stool cultures. Biopsy of the rectal mucosa in Case 1 showed heavy infiltration with lymphocytes and plasma cells. In all four cases resolution was complete by 10 days with the formation of normal or constipated stools and disappearance of blood and mucus. A bariume enema was performed on three of the four patients; in two, changes were compatible with distal idiopathic ulcerative colitis, showing lack of haustration and/or shallow ulceration of the mucosa, and in the third diverticular disease only was demonstrated. It is of interest that a flare-up of diverticular disease and perforation has been recorded in association with NSAIDs (Coutrot et al., 1978; Schwartz, 1981) though in our case the predominant disease was proctocolitis. The time interval from starting the drug to the onset of diarrhoea varied from 2 days to 4 months but the three patients who were re-challenged relapsed within 72 hours. On follow-up all remained well and free of bowel symptoms.

Vane in 1971 first proposed that the action of NSAIDs involved the inhibition of prostaglandin synthesis and the four drugs implicated in these cases are all potent inhibitors of prostaglandin synthesis. As mucosal prostaglandins are known to be increased in active ulcerative colitis (Sharon et al., 1978) and may play some part in the inflammatory response in this condition, drugs of this kind might be expected to have a beneficial effect on the mucosa. Indeed, sulphasalazine and its cleavage product 5-aminosalicylic acid both inhibit prostaglandin synthesis in the rectal mucosa, at high concentrations, although they are less potent inhibitors than indomethacin or flurbiprofen 
(Hawkey \& Truelove, 1983).

However, Levy \& Gaspar (1975) reported proctitis occurring after the use of indomethacin suppositories, the severity of which appeared to be related to the dose. In individuals known to have ulcerative colitis attempts to lower prostaglandin levels in the gut with a short course of oral flurbiprofen, compared with conventional treatment, showed that the patients given flurbiprofen fared significantly worse (Rampton \& Sladen, 1981). Others have shown that local treatment with indomethacin retention enemas failed to produce improvement in distal proctocolitis (Gilat $e t$ al., 1979). Furthermore, ibuprofen has been reported to be associated with an acute relapse of ulcerative colitis after only six tablets (Walt et al., 1984). Rampton \& Sladen (1980) reported four patients with inactive ulcerative proctocolitis in whom the administration of NSAIDs appeared to precipitate relapse and proposed that this might be due to inhibition of synthesis of prostaglandins which may be playing a protective role in the mucosa. Relapse of quiescent ulcerative colitis appears to occur fairly quickly after NSAIDs but in those without underlying colitis, the time interval is more variable. This would be consis-

\section{References}

ATHERTON, L.D., LEIB, E.S. \& KAYE, M.D. (1984). Toxic megacolon associated with methotrexate therapy. Gastroenterology, 86, 1583.

BJARNASON, I., WILLIAMS, P., SO, A., ZANELLI, G.D., LEVI, A.J., GUMPEL, J.M., PETERS, T.J. \& ANSELL, A. (1984). Intestinal permeability and inflammation in rheumatoid arthritis: effects of non-steroidal anti-inflammatory drugs. Lancet, ii, 1171.

COLLINS, J. (1982). Cimetidine induced ulcerative colitis. Medical Journal of Australia, 1, 307.

COUTROT, S., ROLAND, D., BARBIER, J., VAN DER MARCQ, P., ALCALAY, M. \& MATUCHANSKY, C. (1978). Acute perforation of colonic diverticula associated with shortterm Indomethacin. Lancet, ii, 1055.

EDWARDS, A.L., HEAGERTY, A.M. \& BING, R.F. (1983). Enteritis and colitis associated with metenamic acid (letter) British Medical Journal, 287, 1626.

FAM, A.G., PATON, T.W., SHAMESS, C.J. \& LEWIS, A.J. (1980). Fulminant colitis complicating gold therapy. Journal of Rheumatology, 7, 479.

GILAT, T., RATAN, J., ROSEN, P. \& PELED, Y. (1979). Prostaglandins and ulcerative colitis. Gastroenterology, 76, 1033.

GRAHAM, C.F., GALLAHER, K. \& JONES, J.K. (1981). Acute colitis with methyl dopa. New England Journal of Medicine, 304, 1044.

HALL, R.I., PETTY, A.H., COBDEN, I. \& LENDRUM, R. (1983). Enteritis and colitis associated with mefenamic acid. British Medical Journal, 287, 1182.

HAWKEY, C.J. \& TRUELOVE, S.C. (1983). Inhibition of prostaglandin synthesis in human rectal mucosa. Gut, 24, 213. tent with the speed of onset of diarrhoea following rechallenge in our cases.

It is now recognized that, in addition to their involvement in tissue-damaging inflammatory reactions, prostaglandins exert a protective effect on the gastric mucosa when exposed to necrotizing agents such as absolute alcohol and to NSAIDs such as aspirin. This property has been termed cytoprotection by Robert (1979). Mucosal inflammation could result therefore from reduced synthesis of cytoprotective prostaglandins. Alternatively, this may be due to enhancement of intestinal permeability by the NSAIDs thus allowing antigenic material within the lumen increased access to the immune system (Bjarnason et al., 1984).

Although these four cases are uncommon, NSAIDs may cause serious inflammatory bowel disease. Mucosal damage may result from impairment of local prostaglandin synthesis and disturbance of the equilibrium between the cyclo- and lipoxygenase pathways of arachidonic acid metabolism. The development of more specific inhibitors of inflammatory factors and drugs which enhance cytoprotection will be of great value to the clinician.

HICKLING, P. \& FULlER, J. (1979). Penicillamine causing acute colitis. British Medical Journal, 2, 367.

KEAT, E.C.B. \& TANSER, A.R. (1966). Phenindione induced haemorrhagic colitis. British Medical Journal, 1, 588.

LEVY, N. \& GASPAR, L. (1975). Rectal bleeding and indomethacin suppositories. Lancet, i, 577.

PEARSON, D.J., STONES, N.H. \& BENTLEY, S.J. (1983). Proctocolitis induced by salicylate and associated with asthma and recurrent nasal polyps. British Medical Journal, 287, 1675.

PHILLIPS, M.S., FEHILLY, B., STEWART, S. \& DRONFIELD, M.W. (1983). Enteritis and colitis associated with mefenamic acid. British Medical Journal, 287, 1626.

RAMPTON, D.S. \& SLADEN, G.E. (1980). Relapse of ulcerative proctocolitis during treatment with anti-inflammatory drugs. Postgraduate Medical Journal, 57, 297.

RAMPTON, D.S. \& SLADEN, G.E. (1981). Prostaglandin synthesis inhibitors in ulcerative colitis: flurbiprofen compared with conventional treatment. Prostaglandins, 21, 417.

RAMPTON, D.S. \& TAPPING, P.J. (1983). British Medical Journal, Enteritis and colitis associated with metenamic acid (letter) 287, 1626.

ROBERT, A. (1979). Cytoprotection by prostaglandins. Gastroenterology, 77, 761.

SHARON, P., LIGUMSKY, M., RACHMILEWITZ, D. \& ZOR, V. (1978). Role of prostaglandins in ulcerative colitis: enhanced production during active disease and inhibition by sulphasalazine. Gastroenterology, 75, 638.

SCHWARTZ, H.A. (1981). Lower gastrointestinal side effects of non-steroidal anti-inflammatory drugs. Journal of Rheumatology, 8, 952. 
TEDESCO, F.S., VOLPICELLI, N.H. \& MOORE, F.S. (1982) Estrogen- and progesterone-associated colitis, a disorder with clinical and endoscopic features mimicking colitis. Gastrointestinal Endoscopy, 28, 247.

VANE, J.R. (1971). Inhibition of prostaglandin synthesis as a mechanism of action for aspirin-like drugs. Nature, 231, 232.
WALT, R.P., HAWKEY, C.J. \& LANGMAN, M.J.S. (1984) Colitis associated with non-steroidal anti-inflammatory agents. British Medical Journal, 288, 238.

WILlIAMS, R. \& GLAZIER, G. (1983). British Medical Journal, Enteritis and colitis associated with metenamic acid (letter) 287, 1626. 